\title{
The influence of geomagnetic activity on mesospheric summer echoes in middle and polar latitudes
}

\author{
O. Zeller ${ }^{1,2}$ and J. Bremer ${ }^{1}$ \\ ${ }^{1}$ Leibniz-Institute of Atmospheric Physics, 18225 Kühlungsborn, Schloss-Str. 6, Germany \\ ${ }^{2}$ Department of Physics and Astronomy, University of Leicester, University Road, Leicester LE1 7RH, UK
}

Received: 10 November 2008 - Revised: 12 January 2009 - Accepted: 22 January 2009 - Published: 19 February 2009

\begin{abstract}
The dependence of mesospheric VHF radar echoes during summer months on geomagnetic activity has been investigated with observation data of the OSWIN radar in Kühlungsborn $\left(54^{\circ} \mathrm{N}\right)$ and of the ALWIN radar in Andenes $\left(69^{\circ} \mathrm{N}\right)$. Using daily mean values of VHF radar echoes and of geomagnetic activity indices in superimposed epoch analyses, the comparison of both data sets shows in general stronger radar echoes on the day of the maximum geomagnetic activity, the maximum value one day after the geomagnetic disturbance, and enhanced radar echoes also on the following $2-3$ days. This phenomenon is observed at middle and polar latitudes and can be explained by precipitating particle fluxes during the ionospheric post storm effect. At polar latitudes, the radar echoes decrease however during and one day after very strong geomagnetic disturbances. The possible reason of this surprising effect is discussed.
\end{abstract}

Keywords. Ionosphere (Mid-latitude ionosphere; Polar ionosphere) - Radio science (Remote sensing)

\section{Introduction}

Since the end of the 1970s, very strong radar echoes have been observed in the upper mesosphere in $80-90 \mathrm{~km}$ altitude at polar and middle latitudes during summer months (Czechowsky et al., 1979; Ecklund and Balsley, 1981). The observations have been performed mostly with radars at frequencies of about $50 \mathrm{MHz}$. At polar latitudes, these echoes are called polar mesosphere summer echoes (PMSE) due to Röttger et al. (1988), and they occur with $80-90 \%$ during the main part of the observation period (June until middle of August). For details see Bremer et al. (2006). The corresponding echoes observed at middle latitudes are desig-

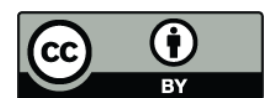

Correspondence to: J. Bremer

(bremer@iap-kborn.de) nated as MSE - mesospheric summer echoes. The occurrence of MSE is much lower than for PMSE, its mean maximum value some days past summer solstice is only about $7 \%$ of the time (Zecha et al., 2003). The requirement for radar echoes are electron density variations at scales of half the radar wavelength (Bragg-scale) and the existence of charged aerosols (mainly small ice particles) which occur due to low mesospheric temperatures preferably during summer at polar (and with slightly enhanced temperatures also at middle) latitudes. Such ice particles which have simultaneously been observed by lidar measurements of noctilucent clouds (von Zahn and Bremer, 1999) reduce the electron diffusivity and prevent thus the fast destruction of the irregularities in the electron density necessary for the radar backscattering. The detailed physical background of (P)MSE is comprehensively described in Kelley et al. (1987), Cho and Röttger (1997), and more recently in Rapp and Lübken (2004).

The electron density in the ionosphere strongly depends on the solar activity. In this paper mainly the impact of precipitating high energetic solar and magnetospheric particles on (P)MSE is discussed. Such particles cause variations of the ionisation of the Earth's ionosphere as well as of the geomagnetic field components. Whereas energetic electrons with energies between about $1-20 \mathrm{keV}$ are responsible for the ionisation in the E-layer and therefore also for the geomagnetic activity, in the D-layer energies between about $30-100 \mathrm{keV}$ are necessary. Assuming a connection between both parts of the above mentioned energy ranges we may assume that the geomagnetic disturbances can be used as a rough indicator for precipitating particle fluxes which can create ionisation enhancements also at mesospheric heights and may thus influence (P)MSE.

Until now, several investigations have been carried out with mesospheric VHF radar echoes in connection with geomagnetic activity. Such investigations have often been made for single events or relatively small data sets (e.g. Bremer et al., 1995; Rapp et al., 2002; Barabash et al., 2004). Analyses

Published by Copernicus Publications on behalf of the European Geosciences Union. 
Table 1. Technical details of the VHF radars in Andenes and Kühlungsborn for investigations of (P)MSE.

\begin{tabular}{lll}
\hline Radar & ALWIN & OSWIN \\
\hline Location & Andenes & Kühlungsborn \\
Geogr. Coordinates & $69.3^{\circ} \mathrm{N} ; 16.0^{\circ} \mathrm{E}$ & $54.1^{\circ} \mathrm{N} ; 11.8^{\circ} \mathrm{E}$ \\
Frequency & $53.5 \mathrm{MHz}$ & $53.5 \mathrm{MHz}$ \\
Peak power & $36 \mathrm{~kW}$ & $36 \mathrm{~kW}(72 \mathrm{~kW})$ \\
Pulse Length & $2 \mu \mathrm{s}$ & $2 \mu \mathrm{s}$ \\
Range resolution & $300 \mathrm{~m}$ & $300 \mathrm{~m}$ \\
Height range & $75-95 \mathrm{~km}$ & $75-95 \mathrm{~km}$ \\
\hline
\end{tabular}

with greater data volumes are shown in Bremer et al. (2000, 2001) and Barabash et al. (2002) concentrating mainly on the diurnal variation of the correlation between PMSE and geomagnetic activities. Other investigations estimate the correlation between monthly mean values of (P)MSE and geomagnetic indices (Bremer et al., 2006).

The present paper concentrates on the comparison of daily mean values of (P)MSE and of the geomagnetic activity specially for time intervals with clear deviations (positive and negative) from the corresponding monthly mean values of the geomagnetic activity.

\section{Data}

The VHF radars used for the investigations of (P)MSE are the ALWIN radar at Andenes $\left(69.3^{\circ} \mathrm{N} ; 16.0^{\circ} \mathrm{E}\right)$ and the OSWIN radar at Kühlungsborn $\left(54.1^{\circ} \mathrm{N} ; 11.8^{\circ} \mathrm{E}\right)$, both working at $53.5 \mathrm{MHz}$. Some technical details of both radars are summarized in Table 1. More detailed information can be found for the ALWIN radar in Latteck et al. (1999) and for the OSWIN radar in Zecha et al. (2003). As the most technical properties of the ALWIN- and OSWIN radar agree the differences of the derived properties of mesospheric summer echoes in polar and middle latitudes are mainly caused by geophysical reasons.

For investigations of MSE, radar data were taken from the summer months of the years 1998 and 2000-2006 whereas for PMSE the data were used from observations in 19992005. For each day we have calculated the percentage of time with echoes. Presence of echoes was defined as signal-tonoise ratio greater than a reasonable threshold value $S_{N R}$ min . The used $\mathrm{SNR}_{\min }$ values were already described in Bremer et al. (2006) in detail (for the ALWIN radar: $\mathrm{SNR}_{\min }=4 \mathrm{~dB}$ for the years $1999-2003$ and $2005, \mathrm{SNR}_{\min }=1 \mathrm{~dB}$ for 2004 ; for the OSWIN radar: $\mathrm{SNR}_{\min }=3 \mathrm{~dB}$ for the years 1998 and

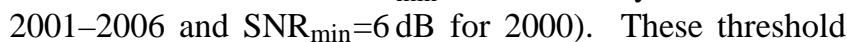
values are for the investigations in this paper, however, of less importance.

For the description of the geomagnetic activity the global $A_{p}$ index and local $K$ indices are used in this paper. They characterize variations of the geomagnetic field components due to the impact of high energetic particles (mostly electrons). The local $K$ index is derived from the maximum difference of the horizontal magnetic field components within 3-hourly intervals using whole numbers between 0 (very quiet) and 9 (extremely disturbed) in a quasi-logarithmic scale. The local daily mean activity index $\Sigma K$ is the sum of the 8 local 3-hourly $K$ values.

The planetary $K_{p}$ index is estimated from $K$ values of 13 selected magnetic observatories. From these quasilogarithmic 3-hourly $K_{p}$ values linear $a_{p}$ values are derived. The daily mean of these 8 global 3-hourly $a_{p}$ values gives the linear daily planetary geomagnetic $A_{p}$ index. Quiet conditions can be described by $A_{p}$ values lower than about 20 whereas strong geomagnetic disturbances are signed in this paper by $A_{p}$ values greater than about 90 .

For the comparison with (P)MSE, the $A_{p}$ data are used from NOAA (1998-2006). Additionally the $K$ indices at Niemegk, Germany $\left(52^{\circ}\right.$ N) (NGK, 1998-2006) have been used for the investigations of the MSE over Kühlungsborn and the $\mathrm{K}$ data at Troms $\varnothing$, Norway $\left(69^{\circ} \mathrm{N}\right)$ (TGO, 1999 2006) for the PMSE over Andenes.

\section{Results and discussion}

Enhanced particle precipitation provides an increase of the electron density as well-known from particle events in the auroral zone and the polar cap. But also changes of the temperature in the meso- and lower thermosphere are probable. However, it is not quite clear if the temperature always increases as expected from some model calculations (Roble et al., 1987; Barabash et al., 2004) and observations (von Savingny et al., 2007). Recent model results from Jackmann et al. (2007) gave decreasing temperatures in most cases of the investigated events. Also temperature observations with meteor radars in middle (Juliusruh, $54^{\circ} \mathrm{N}$ ) and in polar latitudes (Andenes, $69^{\circ} \mathrm{N}$ ) gave strong indications for such temperature decreases (Singer et al., 2008) which may have a dynamic cause.

In the following sections the influence of precipitating high energetic particles upon (P)MSE will be separately investigated using VHF radar observations in middle and polar latitudes. As indicator of precipitating particle fluxes local or global geomagnetic activity indices are used.

\subsection{Middle latitudes}

The investigation of the impact of geomagnetic activity on VHF radar echoes in the summer mesosphere has been performed by superimposed epoch analyses. For middle latitudes, time intervals of 9 days length have been selected around a pronounced geomagnetic activity peak with $A_{p \max }>35$ as well as intervals around an activity peak with $\Sigma K_{\max }>30$ ( $\Sigma K$ : the daily sum of the $8 K$ values 

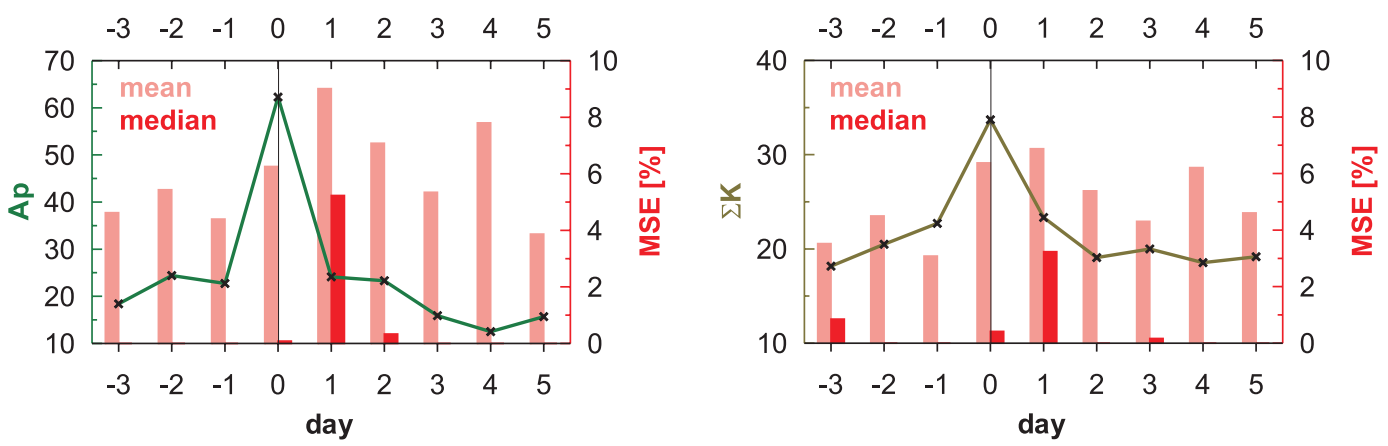

Fig. 1. Left part: Superimposed epoch analysis of the MSE occurrence rates (red bars) and the corresponding $A_{p}$ indices (green curve) using for key day 0: $A_{p} \max \geq 35$ basing on 22 intervals during 1998-2006. Right part: As left panel but using here the local geomagnetic indices $\Sigma K$ at Niemegk with $\Sigma K_{\max } \geq 30$ for 23 intervals.
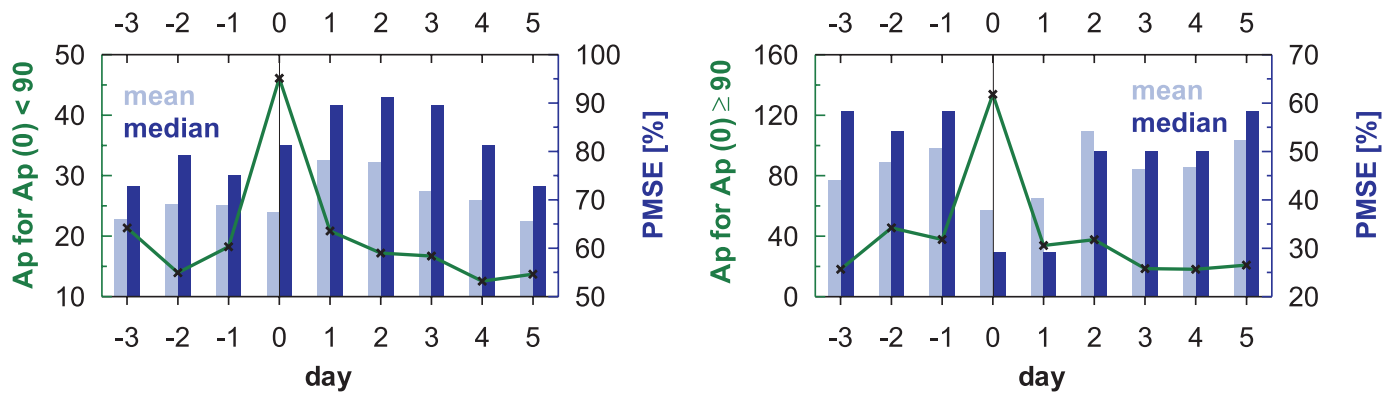

Fig. 2. Superimposed epoch analyses of the PMSE occurrence rates (blue bars) and the corresponding $A_{p}$ indices (green curve) using for key day 0: 35 $\leq A_{p \max }<90$ basing on 20 intervals (left panel) and for $A_{p \max } \geq 90$ basing on 9 intervals (right panel) during 1999-2005.

at Niemegk). Using the MSE observations in 1998 and 2000-2006 altogether 22 intervals have been found with $A_{p \max }>35$ and 23 intervals with $\Sigma K_{\max }>30$. The intervals have been selected so that at least 3 days are between adjacent $A_{p}$ maxima. Figure 1 shows the results of the superimposed analyses using the corresponding $A_{p \max }$ or $\Sigma K_{\max }$ values as key day zero. The results of both analyses are very similar thus demonstrating that the choice of the geomagnetic activity index is not important for the investigations presented here. Both results show an enhanced MSE occurrence rate at day zero and a maximum of MSE one day after the maximum of $A_{p}$ and $\Sigma K$ in the mean and the median values. Due to the high variability of the MSE values and the resulting high standard deviations of the mean values, the significance level of the difference between the MSE maximum (day 1) and minimum values (day 5 and day -1 , respectively) is however smaller than $90 \%$. Note also the slightly enhanced MSE values at the days 2-4. The time lag between the maxima of the MSE corresponding to the maxima of the geomagnetic indices as well as the enhanced MSE occurrence rates up to day 4 may be caused by the ionospheric post storm effect whereby high energetic particles captured by the Earth's magnetic field gradually drop down into lower atmospheric layers ionizing them (Bremer, 1998).

\subsection{Polar latitudes}

Comparisons between geomagnetic activity and mesospheric radar echoes in polar latitudes show partly different results compared with middle latitudes. Often a positive correlation between both parameters has been reported (e.g. Bremer et al., 2000, 2001, 2006). In Rapp et al. (2002) however a weakening of the PMSE power during a very strong impact of high energetic particles is found. Due to this fact, two superimposed epoch analyses have been performed. In the first analysis only intervals with $A_{p \text { max }}$ values between 35 and 89 have been chosen whereas in the second analysis $A_{p}$ max values of 90 and more have been used to distinguish between periods with moderate and very strong maxima of geomagnetic activity. The $A_{p}$ index has been applied because maxima of geomagnetic events are highlighted by the $A_{p}$ index much better than by the quasi-logarithmic $\Sigma K$ values. The results are shown in Fig. 2. In case of moderately disturbed intervals of geomagnetic activity, the PMSE occurrence rate is enhanced between day 0 and 4 (left part of Fig. 2) similar to the middle latitude observations (see Fig. 1). Due to the highly variable individual PMSE values the standard deviation is relatively high and therefore the significance level for the difference between the undisturbed mean values before the geomagnetic disturbances and the mean values of the 


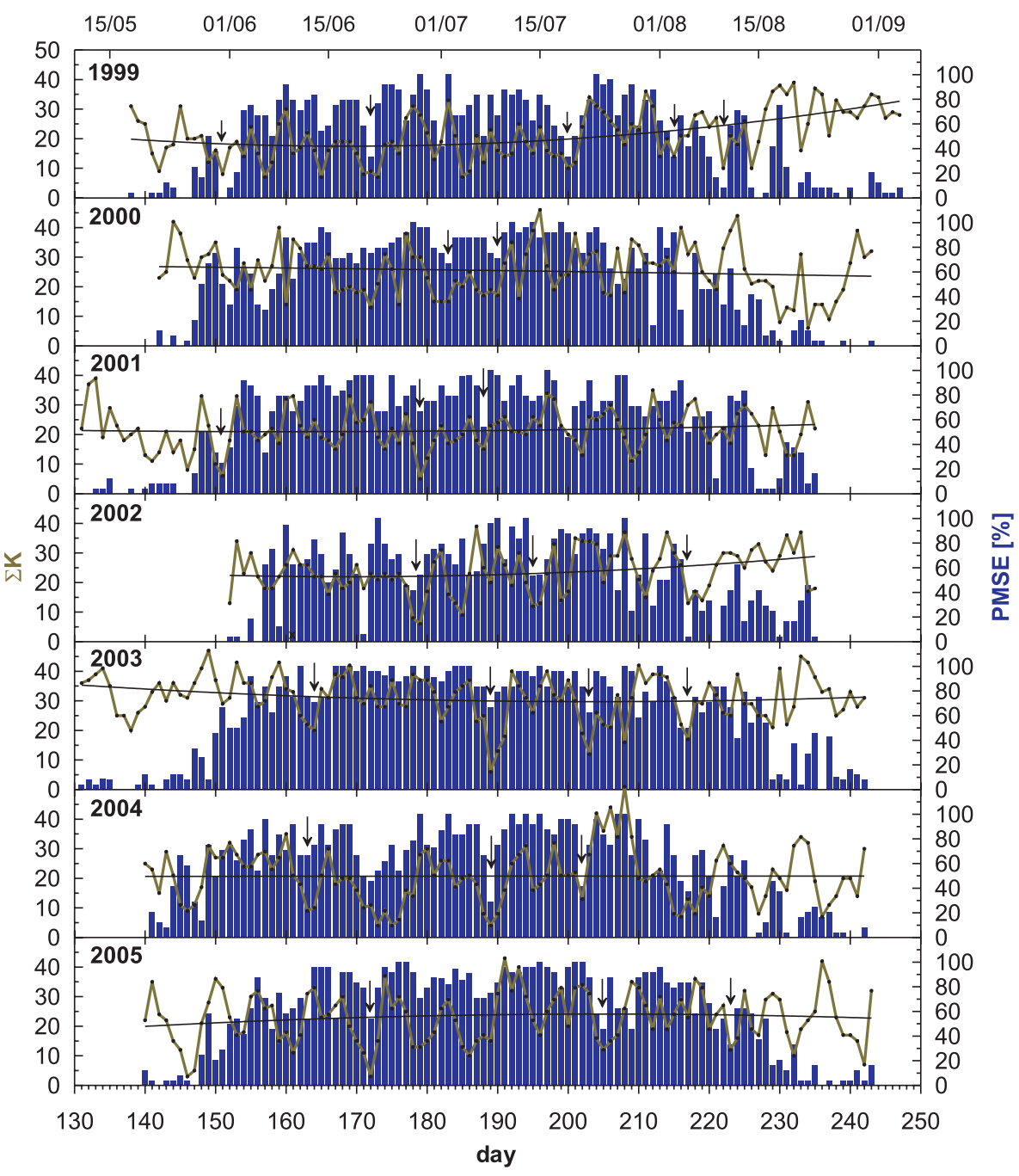

Fig. 3. Seasonal variation of PMSE occurrence rates (blue bars) and of geomagnetic activity $\Sigma K$ at Troms $\emptyset$ (green curves) for different years (1999-2005). The black curves are polynomial fits to demonstrate the mean seasonal variation of $\Sigma K$, arrows show pronounced minima in PMSE and $\Sigma K$.

days $0-4$ below $90 \%$. The maximum of the mean PMSE occurrence rate is at day 1 and for the median values at day 2 . In agreement with the results derived for middle latitudes, the time interval with enhanced PMSE occurrence during days $0-4$ can be explained by the post storm effect. At polar latitudes, this PMSE enhancement during the days 0-4 is clearer than at middle latitudes, in particular in the median value presentation.

In contrast to the results for moderately disturbed periods, the PMSE occurrence rate decreases during very strong geomagnetic disturbances at days 0 and 1 as demonstrated in the right part of Fig. 2 by the mean as well as the median values. The significance level between the maximum and minimum of the mean PMSE is however below $90 \%$ whereas the median values (dark blue bars) show more pronounced differences. The reason for the PMSE decay during and af- ter very strong geomagnetic disturbances is under discussion. Extremely strong events of precipitating high energetic particles cause an increase of the electron density by several orders of magnitude. Therefore, it was assumed by Rapp et al. (2002) that the ratio between charged aerosol and electron density markedly smaller than one should weaken the PMSE strength following a theory developed by Cho et al. (1992). However, results of rocket-born measurements show PMSE also at ratios clearly below 1 down to 0.02 (Blix et al., 2003). Another possible reason for the PMSE decay was proposed by Barabash et al. (2004). Strong precipitating high energetic particles fluxes induce strong electric fields which can cause a transport of charged aerosols. Such lowering of the charged aerosol density would reduce their influence on the reduction of the electron diffusivity and should therefore reduce the PMSE signal. A weakening of the radar signals caused 
by an increasing ionospheric absorption due to markedly enhanced electron densities can be neglected as demonstrated by model calculations of Barabash et al. (2004). Signals of the ESRAD radar in Kiruna, Sweden, whose frequency with $52 \mathrm{MHz}$ is very similar to the frequency of the ALWIN radar, are during strongly enhanced electron densities only slightly reduced by less than $0.5 \mathrm{~dB}$. Another possibility to explain the detected PMSE decrease at days 0 and 1 could be an increasing temperature due to the precipitating particles which could destroy the charged aerosols (ice particles). However, such temperature effects should be small as even the sign of such temperature changes is not quite clear according to various observations and model calculations mentioned above.

A further investigation concerns the PMSE and geomagnetic activity during quiet conditions. Here $\Sigma K$ is used, because geomagnetic variations at quiet conditions are more clearly resolved than by the $A_{p}$ index. Figure 3 shows the daily PMSE occurrence rates with the $\Sigma \mathrm{K}$ values during different summer seasons of the years 1999-2005. At days with pronounced and often also with less pronounced $\Sigma K$ minima, the PMSE occurrence rate is clearly reduced (marked by arrows). Such minima have been observed at three or more times during each season. A very weak geomagnetic activity is connected with a very small flux of precipitating high energetic particles. This leads to a decrease of the electron density and therefore to smaller variations in the electron density which are an essential requirement for the existence of PMSE. During such phases, the ionization is mainly determined by the solar Lyman $\alpha$ radiation ionizing primarily nitric oxide.

The occurrence of simultaneous minima in $\Sigma K$ and PMSE has been tested by means of a superimposed epoch analysis. Here the daily values of $\Sigma K$ are fitted by a polynomial function (black lines of Fig. 3) for each year to describe their seasonal variation. Then intervals with minima of $\Sigma K$ at day 0 have been chosen if the minimum values are at least lower than about 10 below the mean seasonal variation. Figure 4 shows the result of the superimposed epoch analysis using altogether 51 intervals of $\Sigma K$ with the associated PMSE occurrence rate. The $\Sigma K$ minimum at day 0 is clearly connected with a pronounced PMSE minimum. The mean PMSE value of the minimum (day 0) and the highest mean value (day 3) is significantly different with a confidence level of $90 \%$ as shown by the black error bars. The difference between the PMSE values at day 0 and 3 is even more pronounced in the median values. This result confirms that the impact of high energetic particles contributes to an essential part of the ionization and thus to strong VHF radar signals in the D layer at polar latitudes. Therefore, in case of low geomagnetic activity the detected PMSE are only small.

The essential role of electron density and its fluctuations in the D layer for the creation of PMSE could also be confirmed by riometer measurements of cosmic noise absorption (CNA) at Davis $\left(69^{\circ} \mathrm{S}\right.$, Antarctica) where PMSE maxima often occurred during CNA maxima (Morris et al., 2005). The CNA

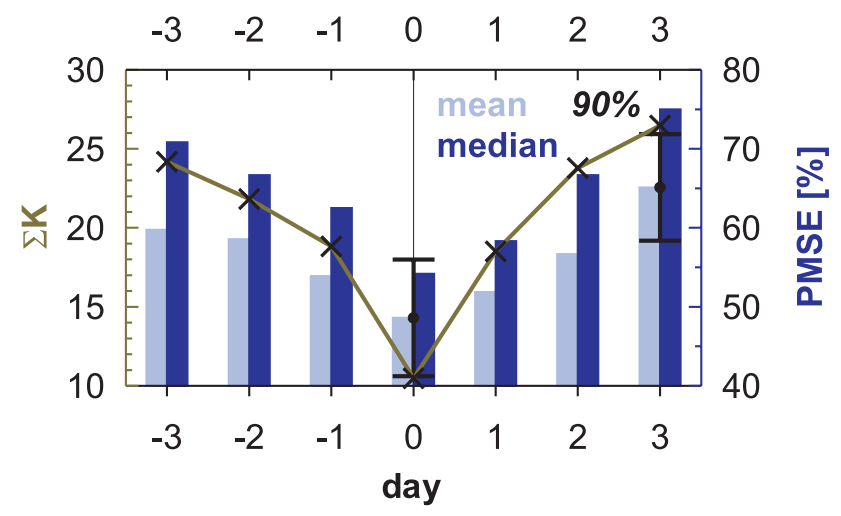

Fig. 4. Superimposed epoch analysis of the PMSE occurrence rates (blue bars) and of the corresponding $\Sigma K$ indices at Troms $\varnothing$ (green curve) during 51 intervals from 1999-2005 using minimum $\Sigma K$ values at key day 0 (for details see text).

is mainly controlled by the electron density in the D layer (Friedrich and Torkar, 1983; Friedrich et al., 2004) and is therefore well correlated with the geomagnetic activity. Examples are also shown in Zeller et al. (2006) during strong solar activity at polar latitudes (but here used for the investigation of polar mesosphere winter echoes).

\section{Summary and conclusion}

In the present paper the connection between daily means of geomagnetic activity and VHF radar echoes in the mesosphere during summer is reported. Superimposed epoch analyses have been applied to marked maxima and minima of the geomagnetic activity and their affect on the associated (P)MSE. The main results can be summarized as follows:

- At middle latitudes, the MSE occurrence tends to be strongest enhanced on day 1 and slightly enhanced 24 days after the maximum of geomagnetic activity.

- A similar result has been obtained for moderate maxima of geomagnetic activity on PMSE at polar latitudes, where there is a PMSE enhancement during days 0-4 after the maximum of geomagnetic activity.

- In both cases the reason of the enhanced (P)MSE during days $0-4$ is that high energetic particles precipitate during and after the geomagnetic disturbance down into lower atmospheric regions causing there an increasing electron density (post storm effect).

- During very strong geomagnetic activity, the PMSE signal markedly decreases at days 0 and 1 . For the explanation of this result several hypotheses have been discussed. Transport of the charged aerosol particle by an induced electric field seems to be an important mechanism. 
- Marked PMSE minima have been detected at minima of geomagnetic activity thus demonstrating the importance of precipitating particles for the creation of PMSE. This effect is statistically significant at polar latitudes.

- The relatively low significance level of the presented superimposed epoch analyses between (P)MSE and geomagnetic activity is mainly caused by the fact that (P)MSE are not only dependent on the geomagnetic activity but also on other parameters (water vapour content, temperature, dynamical conditions).

Especially the effect of strong geomagnetic disturbances onto PMSE needs further investigations in future. Statistical investigations of larger data sets as well as model calculations should be helpful to find a final explanation for this phenomenon.

Acknowledgements. The authors want to thank Ralph Latteck, Werner Singer, Jörg Trautner, and Marius Zecha for their permanent support to run the VHF radars and to analyze the data. The radar experiments at Andenes received funding from the EU 6th framework programme project ALOMAR eARI CT-2003-506208. The authors are also very grateful to two unknown referees for their helpful comments and suggestions.

Topical Editor C. Jacobi thanks T. L. Hansen and another anonymous referee for their help in evaluating this paper.

\section{References}

Barabash, V., Kirkwood, S., and Chilson, P. B.: Are variations in PMSE intensity affected by energetic particle precipitation?, Ann. Geophys., 20, 539-545, 2002,

http://www.ann-geophys.net/20/539/2002/.

Barabash, V., Kirkwood, S., Feofilov, A., and Kutepov, A.: Polar mesosphere summer echoes during the July 2000 solar protonevent, Ann. Geophys., 22, 759-771, 2004, http://www.ann-geophys.net/22/759/2004/.

Blix, T. A., Rapp, M., and Lübken, F.-J.: Relations between small scale electron number density fluctuations, radar backscatter and charged aerosol particles, J. Geophys. Res., 108(D8), 8450, doi:10.1029/2002JD002430, 2003.

Bremer, J.: Post storm effects in middle and subauroral latitudes, Adv. Space Res., 22(6), 837-840, 1998.

Bremer, J., Hoffmann, P., and Hansen, T. L.: Geomagnetic control of polar mesosphere summer echoes, Ann. Geophys., 18, 202208, 2000,

http://www.ann-geophys.net/18/202/2000/

Bremer, J., Hansen, T. L., Hoffmann, P., and Latteck, R.: Dependence of polar mesosphere summer echoes on solar wind and geomagnetic activity, Adv. Space Res., 28(7), 1071-1076, 2001.

Bremer, J., Singer, W., Keuer, D., Hoffmann, P., Röttger, J., Cho, J. Y. N., and Swartz, W. E.: Observations of polar mesospheric summer echoes at EISCAT during summer 1991, Radio Sci., 30(4), 1219-1228, 1995.

Bremer, J., Hoffmann, P., Höffner, J., Latteck, R., Singer, W., Zecha, M., and Zeller, O.: Long-term changes of mesospheric summer echoes at polar and middle latitudes, J. Atmos. SolarTerr. Phys., 68, 1940-1951, 2006.
Cho, Y. N. and Röttger, J.: An updated review of polar mesosphere summer echoes: Observation, theory, and their relationship to noctilucent clouds and subvisible aerosols, J. Geophys. Res., 102(D2), 2001-2020, 1997.

Cho, J. Y. N., Hall, T. M., and Kelley, M. C.: On the role of charged aerosols in polar summer mesosphere echoes, J. Geophys. Res., 97(D1), 875-886, 1992.

Czechowsky, P., Rüster, R., and Schmidt, G.: Variations of mesospheric structures in different seasons, Geophys. Res. Lett., 6(6), 459-462, 1979.

Ecklund, W. L. and Balsley, B. B.: Long-term observations of the Arctic mesosphere with the MST radar at Poker Flat, Alaska, J. Geophys. Res., 86(A9), 7775-7780, 1981.

Friedrich, M. and Torkar, K. M.: High-latitude plasma densities and their relation to riometer absorption, J. Atmos. Terr. Phys., 45, 127-135, 1983.

Friedrich, M., Harrich, M., Torkar, K. M., and Kirkwood, S.: The disturbed auroral ionosphere based on EISCAT and rocket data, Adv. Space Res., 33, 949-955, 2004.

Jackman, C. H., Roble, R. G., and Fleming, E. L.: Mesospheric dynamical changes induced by the solar proton events in October-November 2003, Geophys. Res. Lett., 34, L04812, doi:10.1029/2006GL028328, 2007.

Kelley, M. C., Farley, D. T., and Röttger, J.: The effect of cluster ions on anomalous VHF backscatter from the summer polar mesosphere, Geophys. Res. Lett., 14, 1031-1034, 1987.

Latteck, R., Singer, W., and Bardey, H.: The ALWIN MST radar - technical design and performance, in: Proceedings of the 14th ESA Symposium on European Rocket and Balloon Programmes and Related Research, Potsdam, Germany (ESA SP-437), edited by: Kaldeich-Schürmann, B., 179-184, ESA Publications Division, 1999.

Morris, R. J., Terkildsen, M. B., Holdsworth, A. D., and Hyde, M. R.: Is there a causal relationship between cosmic noise absorption and PMSE?, Geophys. Res. Lett., 32, L24809, doi:10.1029/2005GL024568, 2005.

NGK: Adolf-Schmidt-Observatorium für Erdmagnetismus in Niemegk, http://www.gfz-potsdam.de/pb2/pb23/Niemegk/en/ index.html, 1998-2006.

NOAA: National Oceanic \& Atmospheric Administration, http:// ngdc.noaa.gov/stp/, 1998-2006.

Rapp, M. and Lübken, F.-J.: Polar mesosphere summer echoes (PMSE): Review of observations and current understanding, Atmos. Chem. Phys., 4, 2601-2633, 2004, http://www.atmos-chem-phys.net/4/2601/2004/.

Rapp, M., Gumbel, J., Lübken, F.-J., and Latteck, R.: D region electron number density limits for the existence of polar mesosphere summer echoes, J. Geophys. Res., 107(D14), 4187, doi:10.1029/2001JD001323, 2002.

Roble, R. G., Emery, B. A., Killeen, T. L., Reid, G. C., Solomon, S., Garcia, R. R., Evans, D. S., Hays, P. B., Carignan, G. R., Heelis, R. A., Hanson, W. B., Winningham, D. J., Spencer, N. W., and Brace, L. H.: Joule heating in the mesosphere and thermosphere during the July 13, 1982, solar proton event, J. Geophys. Res., 92(A6), 6083-6090, 1987.

Röttger, J., Hoz, C. L., Kelley, M. C., Hoppe, U.-P., and Hall, C.: The structure and dynamics of polar mesosphere summer echoes observed with the EISCAT 224-MHz radar, Geophys. Res. Lett., 15, 1353-1356, 1988. 
Singer, W., Hoffmann, P, Latteck, R., and Batista, P.: Response of mesospheric temperatures and winds on solar proton events after meteor/MF radar observations, Paper C23-0007-08 presented at the 37th COSPAR Scientific Assembly, Montreal, Canada, 1320 July 2008.

TGO: Troms $\emptyset$ Geophysical Observatory, http://geo.phys.uit.no/ geomag.html, 1999-2006.

von Savigny, C., Sinnhuber, M., Bovensmann, H., Burrows, J. P., Kallenrode, M.-B., and Schwartz, M.: On the dissapearence of noctilucent clouds during January 2005 solar proton events, Geophys. Res. Lett., 34(2), L20805, doi:10.1029/2006GL028106, 2007. von Zahn, U. and Bremer, J.: Simultaneous and common-volume observations of noctilucent clouds and polar mesosphere summer echoes, Geophys. Res. Lett., 26(11), 1521-1524, 1999.

Zecha, M., Bremer, J., Latteck, R., Singer, W., and Hoffmann, P.: Properties of midlatitude mesosphere summer echoes after three seasons of VHF radar observations at $54^{\circ} \mathrm{N}$, J. Geophys. Res., 108(D8), 8439, doi:10.1029/2002JD002442, 2003.

Zeller, O., Zecha, M., Bremer, J., Latteck, R., and Singer, W.: Mean characteristics of mesosphere winter echoes at mid and high latitudes, J. Atmos. Solar-Terr. Phys., 68, 1087-1104, doi:10.1016/j.jastp.2006.02.015, 2006. 